\title{
Role of fasciae in nonspecific low back pain
}

\author{
Gulia Casato (1), Carla Stecco (2), Riccardo Busin (1)
}

(1) Private Clinic, Piovene Rocchette, Italy; (2) Department of Neuroscience, Section of Human Anatomy, University of Padova, Padova, Italy

This article is distributed under the terms of the Creative Commons Attribution Noncommercial License (CC BY-NC 4.0) which permits any noncommercial use, distribution, and reproduction in any medium, provided the original author(s) and source are credited.

\begin{abstract}
More and more evidences show how the thoracolumbar fascia is involved with nonspecific low back pain. Additionally, recent studies about anatomy have shown the presence of a continuity between the thoracolumbar fascia and the deep fascia of the limbs; but actually, a dysfunction of just the thoracolumbar fascia or of the tightly contiguous myofascial tissue is generally recognized as possible cause of nonspecific low back pain. Five patients among those affected by nonspecific low back pain were manipulated just on those fascial spots that were painful, when palpated, and located in other areas of the body than the low back one. Each patient reported a clinically significant reduction of the painful symptoms (a Pain Numerical Rating Scale score difference $\geq 2$ ) straight after the manipulation. A dysfunction of the myofascial tissue that is not tightly contiguous with the symptomatic area is then suggested to be taken into consideration among the causes of nonspecific low back-pain.
\end{abstract}

Key Words: Fascia, nonspecific low back pain, limb myofascial manipulation, fascial continuity, case series.

Eur J Transl Myol 29 (3): 159-163, 2019

Nonspecific low back pain has a multifactorial etiology. Current literature does not support a definitive cause for initial episodes of low back pain. ${ }^{1}$ Under a pathoanatomical point of view, any innervated structure in the lumbar spine can cause symptoms of low back pain. These potential structures are the muscles, ligaments, dura mater and nerve roots, zygapophyseal joints, annulus fibrosis, vertebrae and thoracolumbar fascia. From 1939, the deep fascia has been recognized as one of responsible tissues for the low back pain. ${ }^{2}$ In particular, among the deep tissues of the lumbar region, the thoracolumbar fascia is the most sensitive to chemical stimulation. Thus, a main contribution to the rise of nonspecific low back pain has been attributed to it. ${ }^{3}$ A lot of free and capsulate nerve endings, including the Pacini's and Ruffini's corpuscles, have been found in the thoracolumbar fascia. Moreover, they are tightly connected to the surrounding fibers of collagen and to the fibrous stroma which the fascia is made of. That innervation is not homogeneous. It differs depending on the substrate. A bigger number of sensory nerve endings, presumably also nociceptive, has been found in the superficial substrate of the posterior lamina of the thoracolumbar fascia. ${ }^{4}$ The injection of growth factors into the fascia of the erector spinae muscle at lumbar level causes a sensitization of the deep layers of the tissue to pressure and chemical stimulation with an acid solution lasting more than two weeks. ${ }^{5}$ Furthermore, after being sensitized, those free nerve endings will be more and more stimulated when the fascia is strained by the contraction of the muscles. A layer of hyaluronic acid produced by specialized fibroblasts, called "fasciacytes", has been identified within the loose connective tissue, placed among the substrates of the deep fascia, and between the same deep fascia and the muscle tissue. ${ }^{6}$ That layer helps the several fascial substrates in sliding, but this would be compromised in case of an alteration to the density of the layer creating abnormal tensions within them. Speaking about that, an average $20 \%$ decrease in the deformation of the thoracolumbar fascia during the passive lumbar flexion has been detected in patients affected by chronic non-specific low back pain comparing to healthy subjects, ${ }^{7}$ highlighting how the same low back pain can be caused by an alteration to its intrinsic connective tissue. Nevertheless, no treatments having the myofascial tissue as a target are mentioned in the lately guidelines regarding low back pain. ${ }^{1}$ Moreover, in the cases considering the fascial tissue, a dysfunction of just the thoracolumbar fascia or of the tightly contiguous myofascial tissue is generally recognized, not a dysfunction of the entire anatomically connected fascial tissue. ${ }^{8}$ Recent studies about anatomy have shown the 


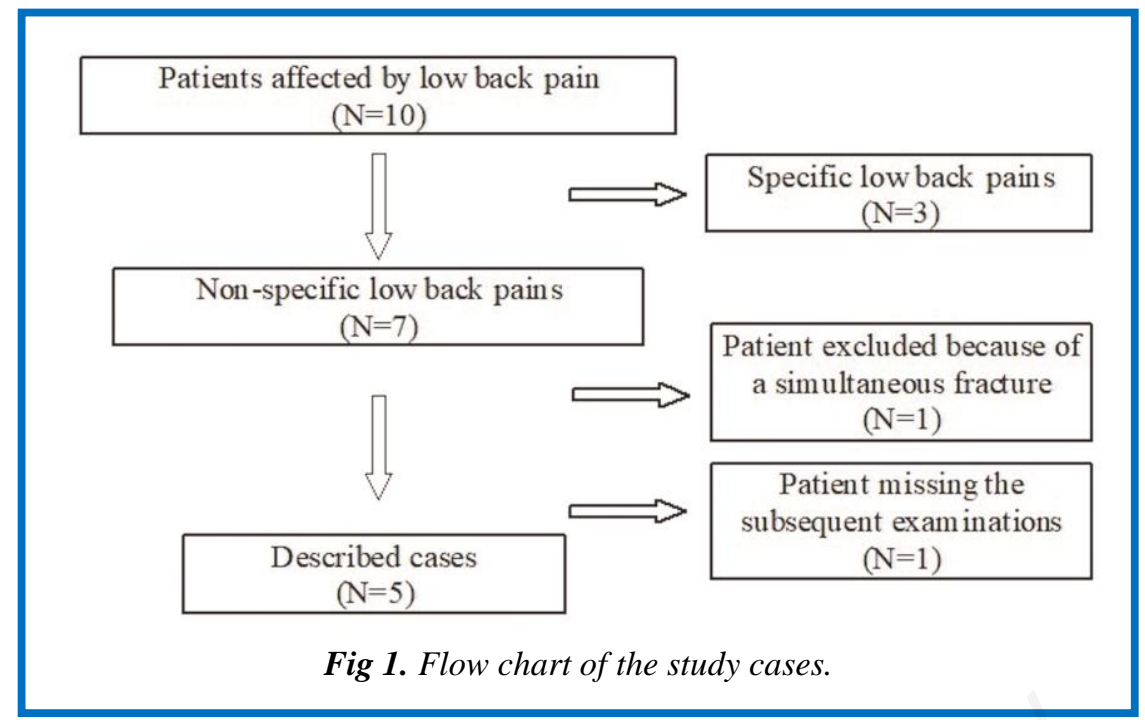

presence of a continuity between the thoracolumbar fascial and the deep fascia of the limbs. ${ }^{9}$ According to these studies, the posterior lamina of the thoracolumbar fascia continues distally with the gluteal fascia and the fascia lata, ${ }^{10}$ while it incorporates the trapezius and the latissimus dorsi proximally. It then has a more distal myofascial expansion within the brachial fascia. ${ }^{11}$ Several more distal myofascial expansions guarantee an anatomical continuity until hands and feet. This collection of clinic cases arises from the hypothesis that, in the case of non-specific low back pain, the feeling of pain at lumbar level could be caused by an alteration of the fascial tissue placed in a different region of the body than the lumbar area and surroundings. That region could be the limbs, according to the Fascial Manipulation ${ }^{\circledR}$ interpretation and in light of the nowadays knowledge regarding the fascial anatomy and histology.

\section{Materials and Methods}

The cases of low back pain were recorded in May 2015 (Figure 1). Those came to an outpatient physiotherapy clinic, with or without symptoms at the inferior limbs. Starting with ten patients, the cases of specific low back pain were excluded, i.e. the cases which did not follow the guidelines of the American College of Sports Medicine. ${ }^{12}$ Thus, the parameters used for excluding were the presence of serious spinal pathologies (e.g., tumors, fractures, inflammatory diseases), previous spinal surgery, nerve root compromise, cardiorespiratory illnesses and pregnancy. Eventually, there have been 5 clinic cases studied ( 4 women, 1 man; aged between 40 and 62 years old), 3 (case 1, 2 and 3 ) affected by acute low back pain (less than 3 months) and 2 (case 4 and 5) by chronic low back pain (more than 3 months). An anamnesis, a general examination and, if necessary, a functional testing were collected for each patient. Following the Fascial Manipulation ${ }^{\circledR}$ assessment model, ${ }^{13}$ movement tests were carried out, i.e. the active flexion, extension, lateral flexion and rotation of the lumbar area plus a palpation of the trunk, legs and forearms, meaning the palpation of the fascial points followed by the identification of the more altered one. Each of these fascial points has a precise anatomical location. That corresponds to the point of the deep fascia where field lines generated by the motor units responsible for moving a joint in a specific direction converge. ${ }^{13}$ It is always at a distance from the actual site of pain. Only altered spots result painful when palpated.

The outcome measures were:

- the pain intensity during the most painful active movement, recorded through the Pain Numerical Rating Scale (NRS) ${ }^{14}$

- the range of motion (ROM) (in ${ }^{\circ}$ ) of the active lumbar flexion, measured thanks to an inclinometer by the difference between the ROM at T12 level and that at the sacrum level, ${ }^{15}$

- the ROM (in cm) of the lumbar active extension, measured thanks to a measuring tape according to the Modified Schober Test; ${ }^{16}$

- the disability revealed asking the patients to fill the Italian version of the "Roland and Morris Disability Questionnaire". ${ }^{17}$

The intensity of the pain was measured before and after each treatment session and during the subsequent examinations which took place at one, three and six months after the last treatment. The ROM was measured before and after each treatment session, and during the subsequent visit which took place one month after the last treatment. The "Roland and Morris Disability Questionnaire" was asked to be filled during the starting examination and the subsequent ones at one, three and six months after the last treatment. The patients have been asked about possible negative or side effects caused by the treatment since the second session on and during the one, three and six months visits after the last treatment. The treatment was a manipulation of the most altered fascial spots of the limbs found with the palpation (Figure 2 ), which was done using the physiotherapist's elbow or knuckle. The five patients were treated by the same 


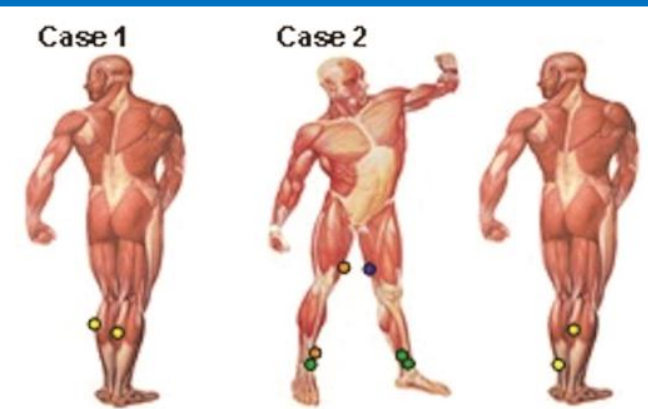

Fig 2. Spots manipulated on the five patients.

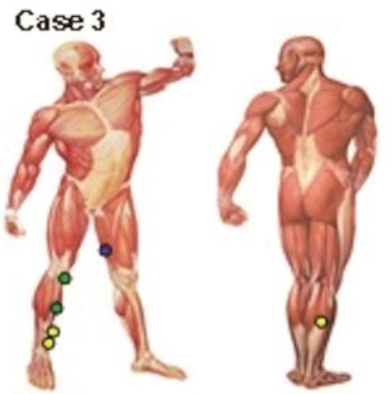

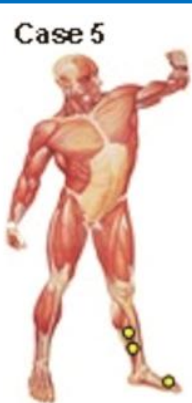

Reprinted with permission from $3 B^{-}$ 4006516/14 The Human Musculature Chart, back/front (c) 3B Scientific GmbH, Germany, 2019

www.3bscientific.com

practitioner. The strength applied by the physiotherapist depended on the patient's ability to endure the pain. The spot was manipulated until the patient had reported the disappearance or a decrease of the strong pain at least by $50 \%$. That can take 2 to 10 minutes, depending on the chronicity and the thickness of the densification arisen over the time. ${ }^{13}$ The number of the treated spots during one session changed depending on the patient considering the densified spots found and the time needed to manipulate them. The direction of the manipulation is not always transverse to the fibers and not always done plumb. Instead it keeps changing with the aim of searching for the strongest friction against the fascia. ${ }^{13}$ Each session, including examination and treatment, lasted forty-five minutes. There was at least one week between two sessions so that there could be a complete regression of the inflammatory phase caused by the treatment. The number of sessions changed depending on the response of the symptoms (Table 1).
When the complete healing of the pain was obtained (NRS score $=0$ ), no more treatment sessions would have been planned but only follow-ups after one, three and six months. During the treatment and in the six months after the last section, the patients have not assumed medicines and have not undergone to other physical therapies.

\section{Results}

Each patient reported a clinically significant reduction of the painful symptoms (a NRS score difference $\geq 2)^{18}$ straight after the manipulation. That reduction of the pain has been found since the first session in the cases 1, 3, 4, 5 ; while in the case 2 it took place during the third session thanks to the treatment of a fascial spot at the distal third level of the gracilis muscle of the left thigh (Figure 3). The lumbar flexion ROM did not show any change; while in three cases, where the treatment focused on the inferior limbs, a clinically significant increase $\left(\geq 5^{\circ}-10^{\circ}\right)^{19}$ of the overall range of motion of the distal joints was observed. Indeed, the same grade of rise in ROM was found at T12

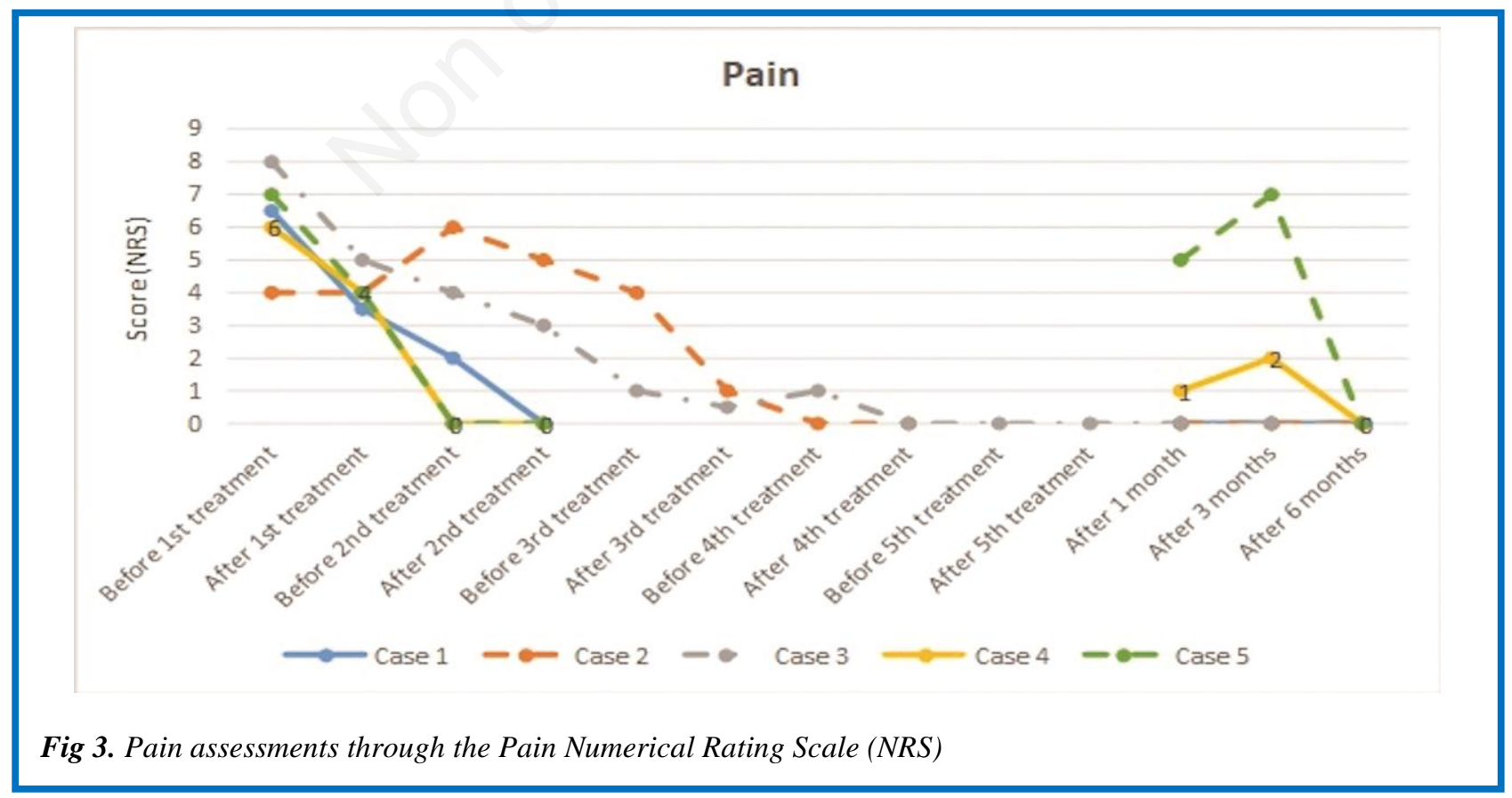


Table1. Number of sessions and total lenght of treatment from the first to the last session.

\begin{tabular}{|l|c|c|}
\hline Case & $\begin{array}{c}\text { Number of } \\
\text { sessions }\end{array}$ & $\begin{array}{c}\text { Lenght of } \\
\text { treatment }\end{array}$ \\
\hline 1 & 2 & 9 days \\
\hline 2 & 4 & 49 days \\
\hline 3 & 5 & 63 days \\
\hline 4 & 2 & 7 days \\
\hline 5 & 2 & 12 days \\
\hline
\end{tabular}

and S1 level in these cases after manipulation. A clear improvement (ROM increase > 100\%) of the lumbar extension was observed when the arms had been treated (case 4). The subsequent examinations after one, three and six months pointed out the conservation of the complete resolution of the symptoms and the disability in cases 1,2 and 3, a partial conservation in case 4, and a relapse in the fifth one (Figure 3). A numbness at the level of the treated spots was the only side effect recorded in common, and its duration could vary between 1 and 5 days. There was a temporary increase in the painful symptomatology in the cases 2 and 3 after one of the treatment sessions. The local inflammatory reaction would be the cause of that and it was due to the manipulation of the loose connective tissue. ${ }^{13}$

\section{Discussion}

The results obtained make us suppose that an alteration of the myofascial tissue could play a role in the etiology of non-specific low back pain, even if not strictly located close to the areas surroundings those where the pain is detected. In fact, the thoracolumbar fascia has a specific basal tension in physiological conditions which lets it to perceive the contraction of the underlying muscles thanks to the local mechanoreceptors. An alteration to the density of the hyaluronic acid layer, which is present in each part of the fascia anatomically contiguous to the thoracolumbar one, can modify the field lines of traction within the fascial tissue creating an alteration to the basal tension of the thoracolumbar fascia thus stimulating its mechanical nociceptors. The manipulation of those fascial densifications can cause a decrease of tension of the thoracolumbar fascia. That can be enough to restore the correct functionality of those receptors. According to the interpretive Fascial Manipulation ${ }^{\circledR}$ model, if the symptomatology occurs again it will be probably due to a non-complete treatment of the manipulated spots or to the presence of other densified spots along the contiguous fascial tissue. In this study, possible altered spots at the trunk level were not treated; that to monitor the effect of the only manipulation of the limbs over the time. Each patient agreed with that. The first palpation assessment revealed the presence of densified spots exactly along the recurring patients' trunks. These were properly those patients affected by chronical symptoms. This would suggest the need of further treatments in chronical patients, even if the symptoms disappear after the limbs' treatment. In these cases it would be appropriate to manipulate those possible altered spots located in the trunk. The lumbar pain perception is decreased by the myofascial tissue manipulation of the limbs in the nonspecific low back pain cases. The anatomic fascial continuity between the thoracolumbar area and the deep fascia of the limbs can explain this phenomenon. In fact, a previous trauma or an overuse of the limbs can alter density of hyaluronan that is present among the sliding layers of the deep fascia of the limbs. That causes an alteration of the tension balance of the thoracolumbar fascia with a consequent modified sprain of its embedded free nerve endings resulting in pain. The treatment of just the lumbar district would implicate a temporary result because it is not focused on the resolution of the primary cause of the dysfunction. Just the limbs were manipulated in this study to evaluate only the effect of their manipulation. If modifications are found with the palpation of the trunk too, its manipulation would be useful for a better result, especially in chronic patients. A dysfunction of the myofascial tissue that is not tightly contiguous with the symptomatic area is then suggested to be taken in consideration among the causes of nonspecific low back-pain. The case size of this study is too small to evaluate the effectiveness of the fascial manipulation of the limbs in nonspecific low back pain patients. Future and more appropriate investigations are necessary, such as a random controlled study, to verify that the results obtained in this case series are not caused by a placebo effect. Those studies should involve big number of individuals to analyze the incidence of the myofascial dysfunction on the etiology of low back pain and to indentify the characteristics of the possible subgroup of patients affected by low back pain, which would have a benefit from a manipulation treatment of the myofascial tissue of the limbs.

\section{List of acronyms}

NRS - Pain Numerical Rating Scale

ROM - range of motion

\section{Authors contributions}

The authors contributed equally.

\section{Acknowledgments}

Part of this paper was presented as poster at the 9th Interdisciplinary World Congress on Low Back and Pelvic Girdle Pain, 2016 Oct 31 - Nov 3, Singapore.

\section{Funding None.}

\section{Conflict of Interest}

The authors declare they have no conflicts. 


\section{Ethical Publication Statement}

We confirm that we have read the Journal's position on issues involved in ethical publication and affirm that this report is consistent with those guidelines.

\section{Corresponding Author}

Carla Stecco, Department of Neuroscience, Section of Human Anatomy, University of Padova, via A. Gabelli, 6535121 Padova (PD), Italia.

Tel: +39.049.8272327 - Fax: +39.049.8272319.

Email: carla.stecco@unipd.it

E-mails of co-authors

Giulia.Casato: giuliacasato@yahoo.it

Riccardo Busin: riccardo.busin@tiscali.it

\section{References}

1. Delitto A, George SZ, van Dillen L, et al. Low Back Pain Clinical Practice Guidelines Linked to the International Classification of Functioning, Disability, and Health from the Orthopaedic Section of the American Physical Therapy Association. J Orthop Sport Phys 2012;42:A1-A57.

2. Kellgren JH. On the distribution of pain arising from deep somatic structures with charts of segmental pain areas. Clin Sci 1939;4:35-46.

3. Schilder A, Hoheisel U, Magerl W, et al. Sensory findings after stimulation of the thoracolumbar fascia with hypertonic saline suggest its contribution to low back pain. Pain 2014;155:222231.

4. Tesarz J, Hoheisel U, Wiedenhofer B, Mense S. Sensory innervation of the thoracolumbar fascia in rats and humans. Neuroscience 2011;194:302-308.

5. Deising S, Weinkauf B, Blunk J, et al. NGF-evoked sensitization of muscle fascia nociceptors in humans. Pain 2012;153:1673-9.

6. Stecco C, Stern R, Porzionato A, et al. Hyaluronan within fascia in the etiology of myofascial pain. Surg Radiol Anat 2011;33:891-6.

7. Langevin HM, Fox JR, Koptiuch C, et al. Reduced thoracolumbar fascia shear strain in human chronic low back pain. BMC Musculoskelet Disord 2011;12:203.

8. Ajimsha MS, Binsu D, Chithra S. Effectiveness of Myofascial release in the management of chronic low back pain innursing professionals. J Bodyw Mov Ther 2014;18:273-81.

9. Stecco C. Functional Atlas of the Human Fascial System. Edinburgh: Churchill Livingstone; 2015.

10. Stecco A, Gilliar W, Hill R, et al. The anatomical and functional relation between gluteus maximus and fascia lata. J Bodyw Mov Ther 2013;17:512-7.

11. Stecco C, Porzionato A, Macchi V, et al. The Expansions of the Pectoral Girdle Muscles onto the Brachial Fascia: Morphological Aspects and Spatial Disposition. Cells Tissues Organs 2007;188:320-9.

12. Kenney LW, Humphrey RH, Mahler DA. ACSM's Guidelines for Exercise Testing and Prescription. Baltimore, MD: Williams \& Wilkins; 1995.

13. Stecco L, Stecco C. Manipolazione Fasciale - Parte pratica. Padova: Piccin; 2007.

14. Dworkin RH, Turk DC, Farrar JT, et al. Core outcome measures for chronic pain clinical trials: IMMPACT recommendations. Pain 2005;113:9-19.

15. Saur PM, Ensink FB, Frese K, et al. Lumbar Range of Motion: Reliability and Validity of the Inclinometer Technique in the Clinical Measurement of Trunk Flexibility. Spine 1996;21:1332-8.

16. Clare HA, Adams R, Maher CG. Construct validity of lumbar extension measures in McKenzie's derangement syndrome. Manual Ther 2007;12:32834.

17. Padua R, Padua L, Ceccarelli E, et al. Italian version of the Roland Disability Questionnaire, specific for low back pain: cross-cultural adaptation and validation. Eur Spine J 2002;11:126-9.

18. Kendric DB, Strout TD. The minimum clinically significant difference in patient-assigned numeric scores for pain. Am J Emerg Med 2005;23:828-32.

19. Kolber MJ, Pizzini M, Robinson A, et al. The reliability and concurrent validity of measurements used to quantify lumbar spine mobility: an analysis of an iphone $\AA$ application and gravity based inclinometry. Int J Sports Phys Ther 2013;8:129-37.

Submission: June, 03, 2019

Revision received: July 03, 2019

Acceptance: July 03, 2019 